\title{
Teknik Produksi Berita Dalam Media Online Era.Id Fitur Lifestyle
}

\author{
Heri Prasetyo ${ }^{1}$, Dedy Zebua ${ }^{2}$, Febriansyah Nataly ${ }^{3}$ \\ ${ }^{1,2,3}$ Sekolah Tinggi Ilmu Komunikasi Indonesia Maju \\ Email correspondent: heripras01@gmail.com
}

\begin{abstract}
Abstrak
Menjabarkan juga mengkaji teknik produksi berita dalam media online era.id fitur lifestyle. Tujuan penelitian ini untuk mengetahui teknik produksi berita dalam media online era.id fitur lifestyle. Metode Penelitian dengan menggunakan pendekatan kualitatif, Jenis dan tehnik pengumpulan data adalah data primer yang diperoleh dari wawancara. Sementara data sekunder diperoleh dari data yang berbentuk buku, web, artikel. Hasil Penelitian Proses Penyajian: Dalam Era.id pada tahap pencarian beritanya adalah mengirim reporter ke tempat-tempat yang berkaitan berita tentang lifestyle, dan pimpinan redaksi memberikan arahan kepada redaksi untuk mencari berita lifesyle melalui artikel, internet, dan lainnya tetapi tidak mengubah teknis penulisan tersebut dengan gaya penulisan era.id dan tidak merubah konteks isi berita tersebut. Dan era.id melakukan peliputan melalui hasil pengamatan isu-isu lifestyle luar negeri dan bekerja sama dengan kantor berita ANTARA dan era.id mempunyai kontributor di setiap wilayah di indonesia untuk mendapatkan berita-berita lifestyle. Kedua tahap penulisan berita, setelah mengumpulkan data dan informasi dari hasil dari liputan, maka reporter langsung mengelola untuk tahapan pengembangan berita (berita ditulis, disunting dan dikembangkan, tidak copy paste). Dan terakhir tahap penyuntingan, setelah ditulis naskah akan disunting oleh redaktur terlebih dahulu sebelum diupload. Kesimpulan agar dapat dibaca oleh masyarakat dan membuat wawasan masyarakat tentang dunia lifestyle lebih mendalam. Saran meningkatkan kembali Teknik produksi berita dalam media onine era.id fitur lifestyle agar fitur ini menjadi fitur yang lebih unggul dan mempunyai kualitas tinggi dari media yang sudah ada sebelumnya.
\end{abstract}

Kata Kunci: teknik produksi berita, penulisan fitur lifestyle.

\begin{abstract}
Describes also examines news production techniques in online media era.id lifestyle features. The purpose of this study was to determine the news production techniques in online media era.id lifestyle features. The research method used a qualitative approach. Types and data collection techniques were primary data obtained from interviews. Meanwhile, secondary data is obtained from data in the form of books, web, articles. Research Results Presentation Process: In Era.id, the news search stage is to send reporters to places related to news about lifestyle, and the editor in chief provides directions to editors to search for lifesyle news through articles, internet, and others but does not change the writing technique. with era.id writing style and does not change the context of the news content. And era.id does coverage through observations of lifestyle issues abroad and in collaboration with the news agency ANTARA and era.id have contributors in every region in Indonesia to get lifestyle news. The second stage of news writing, after collecting data and information from the results of the coverage, the reporter immediately manages the news development stage (news is written, edited and developed, not copy and paste). And finally the editing stage, after writing the script will be edited by the editor first before uploading. Conclusion so that it can be read by the public and make people's insight into the world of lifestyle more deeply. Suggestions to improve news production techniques in online media era.id lifestyle features so that this feature becomes a superior feature and has a high quality than existing media.
\end{abstract}

Keyword: press production techniques, the writing of the lifestyle feature. 


\section{Pendahuluan}

Perkembangan teknologi komunikasi mengalami kemajuan pesat seiring dengan kemajuan ilmu pengetahuan. Dengan peran teknologi dalam proses informasi membantu mengubah pola komunikasi yang dibatasi ruang dan waktu menjadi pola komunikasi informasi tanpa batas. Perkembangan teknologi yang demikian pesat itu juga menyebar luas ke industri media. Salah satunya yaitu media massa. ${ }^{1}$

Media massa merupakan sarana penyampaian komunikasi dan informasi yang melakukan penyebaran informasi secara massal dan dapat diakses oleh masyarakat secara luas. Sehingga masyarakat mudah mendapatkan informasi secara aktual. Kamus Besar Bahasa Indonesia (KBBI) menjelaskan bahwa arti "media" yaitu alat (sarana) komunikasi, seperti koran, majalah, radio, televisi, film, poster dan spanduk. ${ }^{2}$

Media massa baik elektronik, cetak, maupun internet memiliki jangkauan yang luas dan bersifat massal sehingga seluruh lapisan masyarakat di berbagai wilayah dapat memperoleh informasi dan pengaruh media massa tersebut terlihat dari sudut pandang masyarakat, pola pikiran, dan prilaku. Media massa adalah media komunikasi dan informasi yang melakukan penyebaran informasi secara massal dan dapat diakses oleh masyarakat secara massal pula. media massa adalah alat-alat dalam komunikasi yang bisa menyebarkan pesan secara serempak, cepat kepada audience yang luas dan heterogen. ${ }^{3}$

Media massa memiliki karakteristik tersendiri. Karakteristik tersebut seperti Publisitas, dimana informasi disebarluaskan kepada masyarakat atau publik. Universalitas, yaitu pesan yang disampaikan bersifat umum. Kontinuitas, yaitu informasi yang diberikan memiliki kesinambungan, sesuai dengan periode atau jadwal terbitnya. Aktualitas, yaitu informasi yang diberikan selalu hal-hal terbaru dan kecepatan menyampaikan informasi kepada masyarakat. Periodisitas, yaitu informasi yang diberikan tetap ada atau berkala. Misalnya, diedarkan setiap hari, mingguan atau siaran beberapa jam untuk setiap harinya. ${ }^{4}$

Media online berbeda dengan media massa lainnya. Memang, pada dasarnya media online tetap menyampaikan informasi atau berita kepada khalayak. Bedanya, media online memiliki kekhasan, keunggulan, pilar, dan elemen yang tidak dimiliki oleh media massa lainnya. Media online bisa dikatakan sebagai media generasi ketiga setelah media cetak (printed media)-koran, tabloid, majalah, buku, dan media elektronik (electronic media)-radio, televisi, dan film/video". ${ }^{5}$

Media online merupakan salah satu jenis media massa yang populer dan bersifat khas. Kekhasan media online terletak pada keharusan memiliki jaringan teknologi informasi dengan menggunakan perangkat komputer, disamping pengetahuan tentang program komputer untuk mengakses informasi atau berita,keunggulan media online adalah informasi bersifat up to date, real time, dan praktis. ${ }^{6}$

Salah satu media online adalah Era id. Era.id merupakan media online yang menawarkan berita dengan cara yang berbeda untuk menikmati berita, berita yang disajikan untuk generasi milenial secara lugas tapi kekinian, berita berat yang di kemas dengan cara ringan, mudah, jelas, dan dapat di pahami dan di mengerti oleh generasi muda untuk membacanya. Di mana media ini mengkemaskan berita dengan cara praktis, berestetikan, sedehana, dan memiliki nilai informasi berita.

Era.id mempunyai sudut pandang yang berbeda dengan media-media lainnya untuk menilai satu berita, yaitu suatu berita yang kecil di peristiwa itu di jadikan suatu berita yang besar dan penting lalu memberikan edukasi kepada masyarakat. Karena media eri.id ini menjadikan seorang pembaca menjadi bagian dari mereka. Jadi sistem penyajian berita di media era.id itu baik dari kalimat, judul tersebut di sajikan dengan mudah di pahami oleh pembaca Era.id.

Era.id baru berdiri sejak tahun 2017. tapi telah menjadi salah satu media alternatif di negeri ini. Sudut pandang dan cara pengemasan yang berbeda, adalah kunci utama dari segalanya. Pageviews setiap bulannya mencapai 1.000.000 dan Alexa Rank Id, salah satu penyedia jasa rangking untuk website dunia menyatakan bahwa rangking media era.id mencapai 11.668 pada tahun 2019 . 
Era.id memiliki beberapa menu dalam kanalnya, seperti : Berita, podcast, infografik salah satu kanal yang di sukai adalah fitur lifestyle. Dalam sebuah portal website tentunya terdapat penggolongan saluran-saluran mengenai suatu topik atau tema yang saling berkaitan. Kanal dalam KBBI (Kamus Besar Bahasa Indonesia) memiliki arti, "Kanal/ka.nal/ $\mathrm{n}$ terusan; atau saluran;"(https://kbbi.web.id/kanal, diakses pada Selasa, 03 April 2018 pukul 13:40 WIB). Kata kanal berasal dari bahasa Inggris yaitu, Canal yang dalam Wikipedia berarti "canals and navigation are human-made channels for water. In the vernacular both are referred to as 'canals'... A true canal is a channel that cuts across a drainage divide, making a navigable channel connecting two different drainage basins." (https://en.wikipedia.org/wiki/Canal, diakses pada Selasa, 03 April 2018 pukul 13:45 WIB). Penulis menafsirkan bahwa kanal dan navigasi merupakan saluran buatan manusia untuk air. Dalam bahasa sehari-harinya keduanya disebut sebagai 'kanal'. Sebuah kanal yang benar adalah saluran yang melintasi membagi drainase, membuat saluran navigasi yang menghubungkan dua daerah aliran yang berbeda.

Pendapat diatas dapat pula dikaitkan dengan kajian jurnalistik dengan diperkuat melalui pendapat yang menyatakan "Kegiatan surf atau menjelajah, dapat diartikan sebagai eksplorasi web dengan menggunakan mouse untuk berpindah-pindah dalam serangkaian jalur yang terkoneksi, atau disebut dengan link, dari lokasi satu, atau situs web, ke lokasi yang lain".7

Pada saat ini banyak manusia yang kesehariannya tidak lepas dari gaya hidup,maka dari itu era.id memberikan informasi yang lengkap untuk di pahami oleh masyarakat luas tentang aturan gaya hidup dengan baik. Pengertian Gaya Hidup (Lifestyle) adalah pola hidup seseorang di dunia yang diekspresikan dalam aktivitas, minat, dan opininya. Gaya hidup menggambarkan "keseluruhan diri seseorang" dalam berinteraksi dengan lingkungannya, gaya hidup menggambarkan seluruh pola seseorang dalam beraksi dan berinteraksi di dunia. ${ }^{8}$

Berdasarkan ketiga pendapat di atas penulis dapat memahami bahwa kanal merupakan saluransaluran yang dibuat manusia dalam sebuah website dengan maksud untuk melakukan penggolongan tema atau topik tertentu yang berbeda ke dalam suatu halaman web. Fitur sebenarnya diserap dari bahasa asing (Inggris) feature yang kerap digunakan dalam artikel-artikel yang membahas mengenai teknologi maupun media, bisa diartikan sebagai aspek, kualitas, atau ciri khas yang menonjol sehingga menjadi daya tarik suatu produk atau isi dalam berita tersebut. Pada umumnya fitur sering di artikan sebagai keunggulan atau kelebihan. Salah satunya ada pada di media. Media yang mempunyai banyak fitur adalah media Era.id yang mempunyai fitur dengan keunggulan dalam konten dan konteks dalam isi beritanya.

Era.id memiliki beberapa kanal, yaitu Berita, Bicara, Kerja, Visual, Digital, Fitur, Vistory, Pilihan Asyik, Podcast dan Fitur. Kanal Fitur memiliki beberapa pilihan yaitu wisata, kesehatan, yang disukai pembaca adalah Lifestyle. Fitur Lifestyle merupakan saluran yang digunakan era.id untuk menyuguhkan berita, yakni mengkombinasi antara teks, gambar, dan infografis.

Fitur lifestyle ini sama seperti kanal-kanal lifestyle di media lain pada umumnya. Tetapi kanal fitur lifestyle di era.id ini disukai oleh masyarakat luas karena bentuk dari penulisan seperti Angle,Konten,Konteks, dan sudut padang yang berbeda dari media lainnya. Maka dari itu fitur lifestyle di media era.id ini tetap memberikan konteks berita di dalam penulisan fitur lifestyle tersebut. Sehingga masyarakat mengetahui informasi lebih dalam tentang gaya hidup.

Berdasarkan latar belakang di atas,menjelaskan bagaimana cara penulisan berita lifestyle yang baik dan benar kepada masyarakat umum. Karena minat pembaca di fitur lifestyle sangat banyak minat pembacanya. Maka dari itu peneliti tertarik untuk mengambil judul " Teknik Produksi Berita Dalam Media Online Era.Id Fitur Lifestyle".

Tujuan dari penelitian ini adalah untuk mengetahui teknik produksi berita dalam media online era.id fitur lifestyle. 


\section{Metode}

Penelitian ini merupakan penelitian deskriptif dengan pendekatan kualitatif. Penelitian deskriptif yaitu penelitian yang bertujuan membuat deskripsi secara sistematis, faktual, dan akurat tentang faktafakta serta sifat tertentu. Pendekatan kualitatif yang dimaksud sebagai prosedur penelitian yang menghasilkan data deskriptif berupa kata-kata tertulis atau lisan dari orang-orang dan perilaku yang dapat diamati.

Penelitian deskriptif mencoba mencari deskripsi yang tepat yang cukup dari semua aktivitas, objek, proses, dan manusia. Penelitian deskriptif berkaitan dengan pengumpulan fakta dan data secara valid untuk memberikan gambaran mengenai objek yang diteliti. ${ }^{9}$

Penelitian ini menggunakan metode studi kasus, karena dalam penelitian ini peneliti ingin membahas secara khusus hal-hal yang berkenan pada teknik produksi penulisan tentang cara pembuatan konsep penulisan berita yang kreatif dan inovatif sehingga fitur lifestyle era.id menjadi salah satu media online yang banyak di nikmati dan dibaca beritanya oleh masyarakat luas. Walaupun media online era.id ini salah satu media terbaru. Studi kasus adalah memilih target sebagai objek penelitian yang dapat dijelaskan secara terperinci dan komprehensif atau secara medalam. Peneliti ini dimaksudkan untuk memberikan gambaran mengenani suatu proses penulisan berita lifestyle yang baik sesuai SOP supaya minat masyarakat untuk membaca jadi lebih banyak.

Dalam penelitian ini penulis memakai purposive sampling Key informan merupakan seseorang yang memang ahli di bidang yang akan diteliti, sementara informan merupakan orang-orang yang relevan dengan bidang yang diteliti, dimana keterangan dari informan diperoleh untuk mengecek kebenaran atau memperkaya informasi dari key informan, pencarian key informan dan informan harus selektif, sehingga upaya penggalian data bisa dilakukan secara maksimal. ${ }^{10}$

Alasan penulis memilih menggunakan 2 informan karena menurut penulis dari 2 informan tersebut dianggap sudah mampu menjawab dan mewakilkan jawaban dari crew lain yang bertugas. Selain itu alasan penulis memilih Pimpinan Redaksi sebagai key informan serta Redaktur, Editor Penulisan, dan Penulis Berita sebagai informan karena mereka dianggap berkompeten serta memahami seluk beluk dari produksi berita lifestyle karena kedua informan ini bertanggung jawab atas produksi berita lifestyle era.id.

Lokasi penelitian dilakukan di PT. Era Indonesia Digital. Alamat Redaksi jl. Tebet Barat VIII No 35, Tebet Jakarta Selatan, 12810. Waktu pelaksanaan penelitian data di lakukan pada tanggal 01 April sampai 1 Juni 2019.

Data Kualitatif dapat terdiri dari berbagai macam bentuk, foto, peta, wawancara terbuka, observasi, dokumen dan lainnya. Istilah data merujuk pada material kasar yang dikumpulkan peneliti dari dunia yang sedang diteliti. Menurut Patton terdapat tiga jenis data dalam penelitian kualitatif. ${ }^{11}$

Observasi dilakukan untuk mendekatkan peneliti ke orang-orang yang ditelitinya dan ke situasi atau lingkungan mereka yang sebenarnya. Dan peneliti dapat masuk ke lingkungan yang ditelitinya atau yang dikenal dengan observasi partisipatif. Pada observasi ini, peneliti mengamati peristiwa, kejadian, pose, dan sejenisnya disertai dengan daftar yang perlu diobservasi. ${ }^{12}$

Wawancara adalah hasil bersama seorang peneliti dan satu atau lebih anggota. Anggota adalah peserta aktif yang wawasan, perasaan, dan kerjasamanya menjadi bagian penting dari proses pembahasan yang mengungkapkan makna subjektif. Wawancara melibatkan rasa berbagi pengalaman maupun latar belakang untuk mendorong keterbukaan dari informan. ${ }^{13}$

Metode dokumentasi adalah metode pengumpulan data yang datanya diperoleh dari buku, internet, atau dokumen lain yang menunjang penelitian yang dilakukan. Dokumen merupakan catatan mengenai peristiwa yang sudah berlalu. Peneliti mengumpulkan dokumen yang dapat berupa tulisan, gambar, atau karya-karya monumental dari seseorang. ${ }^{14}$ 
Triangulasi merupakan teknik pemeriksaan keabsahan data yang memanfaatkan sesuatu yang lain. Untuk keperluan pengecekan atau sebagai pembanding terhadap data itu, guna untuk mengecek balik derajat kepercayaan suatu informasi yang didapat dalam penelitian kualitatif. Dan tujuan dari triangulasi bukan hanya untuk mencari kebenaran dari beberapa fenomena namun juga untuk mengetahui pemahaman peneliti meningkat atau tidak terhadap hasil temuanya. ${ }^{15}$

Pada penelitian kali ini, penulis menggunakan triangulasi sumber dengan membandingkan atau mengecek ulang data yang sudah didapat dengan pandangan orang yang berkaitan langsung dengan data tersebut. Sumber yang digunakan dalam memastikan kredibilitas data adalah orang yang berkompeten langsung dalam memberikan informasi mengenai teknik produksi berita lifestyle era.id yaitu Pimpinan Redaksi sebagai key informan serta Redaktur, Editor Penulisan, dan Penulis Berita. Peneliti juga membandingkan hasil penelitian dengan hasil wawancara yang dilakukan dengan narasumber.

\section{Hasil dan Pembahasan \\ SOP Dan Tahapan Penulisan Berita Fitur Lifestyle}

Berdasarkan hasil wawancara dengan para informan penelitian yang terdiri dari pimpinan redaktur sebagai keyinforman, editor penulis sebagai informan1 dan production assistant sebagai informan2 terkait SOP dan tahapan penulisan berita fitur lifestyle, menurut Ahmad Sahroji sebagai redaktur selaku keyinforman mengatakan :

Tahapan pertama dalam produksi yaitu mencari berita, sumbernya dari reporter, baik itu berita nasional maupun lifestyle dan berita apapun. Mencari berita juga bisa dilakukan oleh seorang penulis dimana penulis mendapatkan materi dari sumber yang sudah ada sebelumnya atau dari media lain, namun dengan cara pengemasan yang berbeda.

Tahapan kedua dalam produksi yaitu mengedit tulisan berita fitur lifestyle atau berita news melalui redaktur. Supaya berita fitur lifestyle tersebut dapat di pahami oleh kalangan umum.

Tahapan ketiga dalam produksi yaitu mempublikasikan hasil berita fitur lifestyle yang sudah selesai ke media online era.id untuk dapat di baca oleh masyarakat luas.

"Ada 3 sumber SOP dan tahapan teknik penulisan berita fitur lifestyle yaitu. Sumber pertama, mengirim reporter kesuatu tempat untuk mencari materi berita fitur lifestyle atau berita news setelah itu materi dikirim ke kepada redaktur atau editor berita untuk pembuatan materi berupa tulisan dari reporter atau menambahkan bahan tulisan berita tersebut sesuai KBBI. Sumber kedua didapat dari media lain seperti ANTARA dan media lainya karena era.id berkerja sama dengan beberapa media. Sumber ketiga didapatkan dari jurnal, internet, atau menulis ulang berita dan dikemas secara menarik, setelah itu mempublikasikan hasil tulisan maupun foto yang sesuai judul berita fitur lifestyle tersebut ke media online era.id"

\section{Bagaimana Persiapan Teknis Membuat Berita}

Setiap media berita online selalu mempunyai teknis penulisan berita news maupun berita fitur lifestyle dan mempunyi cara untuk mempersiapkan teknis berita tersebut, salah satunya yaitu reporter media online era.id tetapi media online era.id memiliki cara dalam mencari teknis berita. Menurut Whardhani Tsa Tsia sebagai reporter selaku informan mengatakan :

"Persiapan teknisnya misalnya sebelum datang ke tempat liputan otomatis pertama kali harus tahu isu. Karena ketika datang ke suatu tempat engga tahu isu, akan bingung disana akan nulis apa. Jadi ketika sudah tahu isu dan akan ditempatkan dimana saja bisa. Dulu saya liputan di pameran mobil, begitu menguasai isu atau tentang otomotif seperti apa. Tapi ketika dipindahkan ke fasion, saya harus membaca untuk mengejar saya ketinggalan di isu mana. Jadi saya harus tahu isu-isu apa. Yang ke dua 
breakdown ada TOR dari misalnya kantor ngasih TOR. Kaya ngasih kamu cari berita ini yah, kamu cari berita ini yah. Setelah itu kita dateng ke lokasi liputan tersebut"

Berdasarkan hasil wawancara diatas bisa disimpulkan bahwa untuk mendapatkan berita tentang lifestyle bisa dari kantor berita ANTARA atau mengirim reporter kesuatu tempat untuk meliput berita tersebut sesuai arahan dari pimpinan redaktur. Dan setelah mendapatkan berita tersebut melalui reporter, editor penulis merapikan hasil liputan dari reporter yang kurang rapih, tetapi ketika mendapat berita dari media lain atau dari jurnal tidak serta merta plagiat atau copy paste tetapi harus di perbarui lalu dari segi penulisan maupun isi berita tersebut.

\section{Pembeda Fitur Lifestyle di Era.id Dengan Media Lain}

Setiap media berita online selalu mempunyai kanal berita fitur lifestyle, salah satunya yaitu media online era.id tetapi media online era.id memiliki pembeda dalam pengemasan berita fitur lifestyle. Menurut Ahmad Sahroji sebagai pimpinan redaktur selaku keyinforman mengatakan:

"Kanal Fitur lifestyle secara umum pengertiannya sama dengan media lain, pembeda fitur lifesyle di Era.id dengan media lain meliputi penggabungan semua tema atau materi berita berupa fitur kanal tersebut, tanpa membedakan pada setiap tema. Pembedanya dari angel beritanya, contoh misalkan media lain bahas bajunya yang dipakai sama raka, tapi di era.id bahas soal motif dan jenis bahan bajunya.

Seperti itu pembeda dari teknik produksi penulisan berita fitur lifestyle konten is king, konteks is queen. Jadi menanamkan konteks didalam konten. Apa yang ingin diperlihatkan dari judul dan isi berita fitur lifestyle tersebut. Contoh misalkan Jokowi berkunjung ke Medan, itu kontennya. Tapi konteksnya adalah jokowi pergi ke medan dengan sepeda motor barunya, itu namanya konteks. Jadi menanamkan konteks seperti bikin studio photo, itu konten, tetapi konteksnya menanamkan, membuat studio photo yang beda dengan yang lain, itu namanya konteks konteks di dalam konten.

Cara untuk membedainya itu seperti mengambil dari angel menarik. Karena era.id ini media baru jadi kita tidak punya tim yang sebanyak dengan media - media mainstream yang udah terlebih dahulu ada, jadi itu yang kita utamain.

Berdasarkan uraian diatas menyimpulkan bahwa pembeda fitur lifestyle Era.id dengan media lainnya adalah dari pengemasan atau angle teknik penulisan berita fitur lifestyle, menanamkan konteks dalam konten untuk menjadi pembeda dari setiap media online lain pada umumnya.

\section{Pembeda Gaya Tulisan Penulisan di era.id}

Setiap media berita online selalu mempunyai strategi penulisan berita fitur lifestyle yang berbeda, salah satunya yaitu media online era.id tetapi media online era.id memiliki pembeda dan strategi dalam penulisan. Menurut Ahmad Sahroji sebagai pimpinan redaktur selaku keyinforman mengatakan :

"Untuk membedakan gaya tulisan atau strategi pengkemasan tulisan di era.id sendiri dengan di media lain itu agak tipis, ada salah satu media yang mengusung genre itu Jurnalisme data. Jurnalisme data itu jurnalisme yang memang dia banyak menyuguhkan data-data yang cukup komprehensif dan lengkap, dan ini juga digandrungi hampir di beberapa media online terutama yang terkini startupstartup media yang juga sama mengusung genre jurnalisme data itu. Jadi mereka berlomba- lomba untuk mencari data yang cukup lengkap untuk di pakai dibadan berita. Disitulah kita mencari semacam perbedaan. Karena media era.id ini segmentasinya adalah kaum milenial jadi untuk pembedanya adalah tidak banyak memakai data dalam penulisan berita dan isi berita, karena pembacanya yang mayoritasnya kaum milenial kurang peduli dan penulis berita pun boring untuk menulis berita yang banyak menyajikan data. Ada istilahnya yang menyebutkan itu kita lebih senang menyebutnya Jurnalisme Rasa. Jurnalisme rasa itu jurnalisme yang memadukan antara tetap berpijak kepada data dan itu kita memakai pendekatan penulis yang lebih deskriptif terhadap satu isu atau kasus. Contoh 
misalkan kita di Era.id segmentnya milenials, waktu itu kita pernah mengangkat soal bagaimana pilpres Pertarungan Antara Prabowo dan Jokowi. Ketika berita soal isu politik ini diberikan kepada anak-anak muda. Tetapi jika isu politik tersebut di berikan judul Pertarungan Koalisi Pantofel vs Sneakers itu isu politik yang masuk ke lifestyle jadi kita kulitin juga soal bagaimana Jokowi menggunakan outfit yang anak muda banget dia pakai sneakers terus dia datang ke event-event music yang dia hobi cover, contohnya beberapa dikoalisi dia kaya Cah Imin, beberapa datang ke acaraacara event menggunakan kaos bahkan yang casual pakaiannya. Berbeda dengan koalisi Prabowo yang cenderung dia menggunakan pantofel terus pakaiannya rapih, dia datang ke acara budaya, datang ke seminar-seminar politik, seminar-seminar internasional. Jadi itu adalah salah satu cara yang kita ambil di Era.id itu sendiri"

Berdasarkan uraian diatas menyimpulkan bahwa pembeda gaya penulisan berita dan judul berita fitur lifestyle Era.id dengan media lainnya adalah dari pengemasan judul dan teknik dalam gaya penulisan berita fitur lifestyle. Supaya tingkat pembaca berita fitur lifestyle lebih banyak di baca oleh kaum milenial, agar tidak kalah saing oleh media-media online lainnya.

\section{Apa Yang Dibutuhkan Reporter Untuk Mencari Berita}

Setiap media berita online selalu mempunyai reporter penulisan berita news maupun berita fitur lifestyle dan mempunyi cara untuk mencari berita tersebut, salah satunya yaitu reporter media online era.id tetapi media online era.id memiliki cara dalam mencari atau membuat berita. Menurut reporter selaku informan mengatakan :

"Kaya pertama kali kita nyiapin TOR (Term Of reference) adalah perencanaan wawancara atau liputan. TOR itu merupakan panduan umum bagi rencana wawancara dan liputan. TOR sangat penting keberadaan, karena akan membuat wawancara lebih terfokus, jelas arahnya, jelas targetnya, jelas topik yang akan dibahas.TOR akan mempermudah pewawancara memahami poin dan urutan pertanyaan. Namun pertanyaan-pertanyaan yang terdapat dalam TOR tidak bisa dijadikan patokan utama ketika proses wawancara berlangsung karena pertanyaan lain diluar TOR bisa muncul ketika proses, wawancara berlangsung kan kalo nyiapin berita itu kita harus tahu isunya, setelah itu kita bikin breakdown bareng-bareng redaksi kalo di Era.id gitu ya breakdown bareng-bareng redaksi apa yang mau tulis hari itu. Kaya` misalnya isunya apa terus ketika sudah sampai ditempat jadi sudah tahu apa yang mau ditulis, apa yang akan ditulis nantinya. Jadi isunya engga keteteran kemana-mana"

\section{Gatewaching Dalam Fitur Berita Lifestyle era.id}

Tahapan-tahapan untuk bisa menghasilkan berita yang baik tentunya di perlukan observasi yang matang, tahapan tersebut dimulai dari mengumpulkan informasi (input), pembuatan dan publikasi berita (output), tanggapan dari para pembaca (respon). Dalam memperoleh sumber berita khususnya pada fitur berita lifestyle, era.id tidak hanya mendapatkan informasi dari crew yang bertugas, namun informasi tersebut bisa didapatkan melalui user. Hal ini seperti yang dikatakan oleh key informan yaitu

"jadi kita mendapatkan berita tuh bukan hanya dari wartawan yang ada di era.id saja. Tapi kita tuh jadi punya grup WA (whatsapp) nah di dalam grup itu isinya ada banyak wartawan dari media lain. Biasanya tuh kita suka berbagi informasi-informasi disitu. Misalnya ada wartawan dari metro nih, nah dia tau ada kejadian terbaru misalnya aja tentang kebakaran, nah biasanya mereka pada nge share tuh. Jadi kadang dari situ kita bisa dapat sumber berita. Dari sumber berita yang kita dapat tadi langsung kita berangkat ke lokasi untuk liputan,selesai kita liputan baru deh kita bikin beritanya. Setelah berita selesai dibuat baru deh masuk ketahapan pengeditan berita biar sesuai sama KBBI, nah ini dilakukan oleh redaktur. Kalo udah selesai diedit dan sudah fix langsung masuk ketahapan pemostingan berita biar langsung dibaca. Setelah itu baru kita bisa tau gimana respon dari pembaca 
apa mereka tertarik dengan beritanya atau tidak, jika tidak berarti kita harus lebih baik lagi dalam penulisan dan pemilihan berita. Supaya mendapatkan rating pembaca yang bagus buat kedepannya."

Berdasarkan hasil penelitian diatas terkait teknik produksi berita dalam media online fitur lifestyle dalam menyajikan berita fitur lifestyle terbagi menjadi tiga tahapan yaitu, tahapan pertama produksi mencari berita dengan mengirimkan reporter untuk meliput berita mengenai fitur lifestyle, sedangkan penulis redaktur di tugaskan untuk meriset bahan melalui internet, jurnal, maupun media online lainnya, tetapi tidak menyamakan tulisan dan isi berita yang sudah ada. Tahapan kedua menulis berita, foto, atau video yang sesuai dengan tema berita liputan yang telah di kirim oleh reporter, lalu redaktur mengedit penulisan berita hasil liputan dan hasil riset sesuai dengan KBBI (Kamus Besar Bahasa Indonesia) dan di kemas lebih menarik oleh redaktur berita atau editor penulisan berita supaya menjadi pembeda dengan media lain isi dari berita fitur lifestyle tersebut. Jika redaktur mendapatkan berita fitur lifestyle tersebut dari media lain atau dari internet lainnya harus di rubah dan tidak boleh sama isi dan penulisannya dengan berita lain, tetapi tidak merubah makna. Tahapan ketiga yaitu, setelah redaktur berita atau editor penulis berita selesai menulis berita yang sudah sesuai dengan KBBI baru lah beritatersebut diposting pada kanal fitur lifestyle supaya dapat dibaca oleh masyarakat.

Dalam tahap input, kanal fitur lifestyle tidak memberikan keleluasaan pada khalayak untuk mencari dan mengumpulkan berita, dalam arti pada proses pengumpulan tertutup untuk masyarakat, hanya redaksi yang bertanggung jawab untuk mencari dan mengumpukan isu-isu yang akan diangkat.

Untuk tahap output, berita yang telah didapat kemudian diolah dan disajikan oleh bagian redaksi. Redaksi akan menkroscek isu-isu yang tela dipilih untuk dijadikan bahan berita, lalu disunting sebelum disajikan pada khalayak luas. Dan redaksi menulis berita dengan sangat menarik dan dapat di pahami oleh pembaca, supaya minat pembaca fitur lifestyle semakin banyak. Kemudian pada tahap respon, user dapat mengirimkan komentar dan berdiskusi di kolom komentar setelah hasil laporan berita di-upload.

Hasil penelitian juga menunjukkan bahwa proses teknik berita pada kanal fitur lifestyle ini tidak jauh berbeda dengan kanal-kanal berita yang lainnya. Namun yang membedakan proses teknik berita pada kanal fitur lifestyle ini adalah pada tahap pencarian dan pengumpulan berita. Tahap pencarian dan pengumpulan berita pada kanal fitur lifestyle yang diperoleh sumbernya adalah kantor berita. Saat ini Era.id berlangganan kantor berita di daerah di setiap wilayah indonesia. Tentunya Era.id juga berlangganan kantor berita ANTARA yang menjaring kerjasama dengan hampir seluruh kantor berita diseluruh dunia.

\section{Kesimpulan}

Berdasarkan hasil penelitian diatas terkait teknik produksi berita dalam media online Era.id fitur lifestyle terbagi menjadi tiga tahapan yaitu tahap teknik pra produksi, produksi dan pasca produksi. Tahapan pra produksi dimulai dengan reporter dan redaktur menentukan perencanaan-perencanaan pencarian berita fitur lifestyle melalui liputan yang di sertakan foto, internet, dan kantor berita ANTARA untuk mendapatkan isu isu berita news maupun lifestyle, tetapi merubah gaya penulisan sesuai konteks dan tidak copy paste tulisan yang sudah ada. Kemudian tahapan produksi yang dilakukan setelah reporter, redaktur mencari dan mendapatkan berita lalu kemudian di kemas lagi penulisannya dengan baik dan sesuai teknik penulisan Era.id yang memakai gaya penulisannya di minati kaum milenial tetapi sesuai dengan KBBI. Tahap terakhir yaitu tahap pasca produksi yang merupakan hasil dari penulisan berita fitur lifestyle yang akan di publis di fitur lifestyle tersebut, supaya dapat dibaca oleh masyarakat dan membuat wawasan masyarakat tentang dunia lifestyle lebih mendalam.

\section{References}

1. Ahmad A. Perkembangan Teknologi Komunikasi Dan Informasi. Dakwah Tabligh. Published online 2012. doi:10.3386/w18571 


\section{JIKOM \\ Jurnal Ilmiah Komunikasi}

Volume 13, No.01, Maret. 2021

2. Apriadi Tamburaka. Literasi Media: Cerdas Bermedia Khalayak Media Massa. Cetakan ke. Raja Grafindo Persada; 2013.

3. Rini Darmastuti. Media Relations : Konsep, Strategi Dan Aplikasi. Andi Publisher; 2012.

4. Nurudin. Pengantar Komunikasi Massa. PT. Raja Grafindo Persada; 2013.

5. Khomsahrial Romli. Komunikasi Massa. Jakarta. Grasindo; 2016.

6. Yunus. Jurnalistik Terapan. Bandung. Ghalia Indonesia; 2010.

7. Brian K. Williams SC. Using Information Technology: A Practical Introduction to Computers \& Communications.; 2010.

8. Kotler dan Keller. Manajemen Pemasaran, Edisi 12, Jilid 1, PT.Indeks,. Jakarta.; 2017.

9. Basuki S. Metode Penelitian. Jakarta. Penaku; 2010.

10. Dr. Uhar Suharsaputra. M.Pd. METODE PENELITIAN Kuantitatif, Kualitatif Dan Tundakan.; 2014.

11. Emzir. Metodologi Penelitian Pendidikan: Kuantitatif Dan Kualitatif. Rajhagrafindo Persada; 2010.

12. Moleong LJ. Metodologi Penelitian Kualitatif, Cet.; 2018.

13. Neuman WL. Metode Penelitian Sosial: Pendekatan Kualitatif dan Kuantitatif Edisi Ketujuh. Jakarta PT Indeks. Published online 2013.

14. Sugiyono. Metode Penelitian Kuantitatif, Kualitatif dan R \& D.Bandung:Alfabeta. Metod Penelit Kuantitatif, Kualitatif dan R DBandungAlfabeta. Published online 2012. doi:10.1017/CBO9781107415324.004

15. Gunawan I. Metode Penelitian Kualitatif: Teori dan Praktik. Jakarta Bumi Aksara. Published online 2014. 